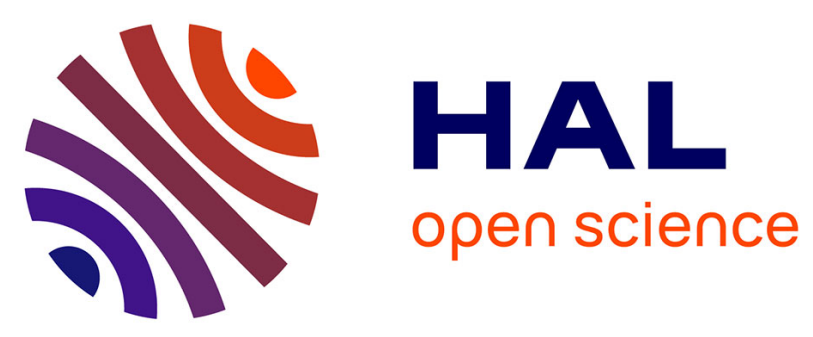

\title{
Unraveling the molecular mechanisms underlying interactions between caseins and lutein
}

Raphaela Araujo Mantovani, Pascaline Hamon, Florence Rousseau, Guilherme M Tavares, Adriana Zerlotti Mercadante, Thomas Croguennec, Said Bouhallab

\section{- To cite this version:}

Raphaela Araujo Mantovani, Pascaline Hamon, Florence Rousseau, Guilherme M Tavares, Adriana Zerlotti Mercadante, et al.. Unraveling the molecular mechanisms underlying interactions between caseins and lutein. Food Research International, 2020, 138, pp.109781. 10.1016/j.foodres.2020.109781 . hal-02977863

\section{HAL Id: hal-02977863 \\ https: / hal.inrae.fr/hal-02977863}

Submitted on 26 Oct 2020

HAL is a multi-disciplinary open access archive for the deposit and dissemination of scientific research documents, whether they are published or not. The documents may come from teaching and research institutions in France or abroad, or from public or private research centers.
L'archive ouverte pluridisciplinaire HAL, est destinée au dépôt et à la diffusion de documents scientifiques de niveau recherche, publiés ou non, émanant des établissements d'enseignement et de recherche français ou étrangers, des laboratoires publics ou privés.

\section{(ㅇ)(1) $\$$}

Distributed under a Creative Commons Attribution - NonCommercial - NoDerivatives 44.0 


\title{
Unraveling the molecular mechanisms underlying interactions between caseins and lutein
}

\author{
Raphaela Araujo Mantovani ${ }^{\mathrm{a}}$, Pascaline Hamon ${ }^{\mathrm{b}}$, Florence Rousseau ${ }^{\mathrm{b}}$, Guilherme \\ M. Tavares ${ }^{\mathrm{a}, *}$, Adriana Zerlotti Mercadante ${ }^{\mathrm{a}}$, Thomas Croguennec ${ }^{\mathrm{b}}$, Saïd Bouhallab ${ }^{\mathrm{b}, "}$

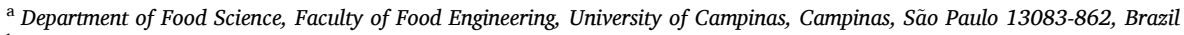 \\ ${ }^{\mathrm{b}}$ INRAE, Institut Agro, STLO, F-35042 Rennes, France
}

\section{A R T I C L E I N F O}

\section{Keywords:}

Lutein

Sodium caseinate

Phosphocaseinate

Interaction

UV-vis spectroscopy

Fluorescence quenching

\begin{abstract}
A B S T R A T
Understanding the food protein binding to bioactive compounds is of utmost importance for the development of efficient protein-based delivery systems. The binding of lutein to sodium caseinate (NaCas) or native casein micelle (PPCN) was investigated at $\mathrm{pH} 7$ to evaluate the effect of casein supramolecular structures on the interaction. Fluorescence quenching, UV-vis spectroscopy, and dynamic light scattering were carried out. Under the medium conditions of interaction analysis (DMSO-water and ethanol-water), lutein exists as H-type aggregates. The investigation of lutein/casein interaction showed a predominantly static mechanism of fluorescence quenching and the presence of two fluorophore populations on NaCas and PPCN, but only one accessible to lutein. Moreover, the Scatchard plot indicated that lutein interacted with both caseins in one binding site. The interaction of lutein with caseins occurred with binding constant $\mathrm{K}_{\mathrm{b}}$ of $10^{5} \mathrm{M}^{-1}$, regardless of casein supramolecular structure.
\end{abstract}

\section{Introduction}

As the proportion of elderly people of the world's population increases, the incidence of chronic-degenerative diseases, the major cause of functional disability among this specific population, also increases. Thus, the development of bioactive-rich products arises as an alternative for maintaining health and life quality for as long as possible in this age group. Carotenoids are natural pigments found in fruits and vegetables. Such a class of bioactive compounds has been proposed to promote human health, mainly due to their antioxidant and anti-inflammatory activities. Lutein is a yellow-orange oxygenated carotenoid that positively modulates some risk diseases that predominate in the elderly, such as age-related macular degeneration (Woodside, McGrath, Lyner, \& McKinley, 2015). However, its addition to fat-free and low-fat products from food and pharmaceutical industries is challenging due to its hydrophobic character. Moreover, carotenoids are sensitive to heat, oxygen, and light (Mercadante, 2007). In this context, carotenoid binding to proteins has been studied aiming at improving its physicochemical stability (Chen et al., 2018; Mora-Gutierrez et al., 2018; Yi, Fan, Yokoyama, Zhang, \& Zhao, 2016).

Caseins constitute up to about 80 percent of milk proteins and are found in milk as supramolecular aggregates, called casein micelles, in which the four casein fractions ( $\alpha \mathrm{S} 1-, \alpha \mathrm{S} 2-, \beta$-, and $\kappa$-casein) are associated by mainly hydrophobic interactions and calcium phosphate nanocluster bridges (Walstra, Wouters, \& Geurts, 2006). These casein micelles are considered natural vehicles of calcium, an important mineral in the human diet, especially for the elderly (Tavares, Croguennec, Carvalho, \& Bouhallab, 2014). To be used as ingredients, casein micelles are obtained from raw skim milk by microfiltration combined with diafiltration with water to remove whey proteins, peptides, lactose, among other components of the water-soluble phase of milk (Broyard \& Gaucheron, 2015). Hence, casein micelles associated with their calcium phosphate are available and called phosphocaseinate (PPCN) (Broyard \& Gaucheron, 2015). Conversely, sodium caseinate (NaCas) is obtained following the neutralization by sodium hydroxide of an acid-precipitate of casein (Walstra et al., 2006). During this operation, the colloidal calcium phosphate is washed out of the casein micelles that lose its native structural organization. Thus, NaCas and PPCN are two caseinrich ingredients but with considerable structural differences. NaCas usually displays a hydrodynamic diameter between 10 and $100 \mathrm{~nm}$, while PPCN has an average hydrodynamic diameter of around $150 \mathrm{~nm}$ and particle size distribution up to $600 \mathrm{~nm}$ (Pan, Zhong, \& Baek, 2013).

\footnotetext{
* Corresponding authors.

E-mail addresses: tavaresg@unicamp.br (G.M. Tavares), said.bouhallab@inrae.fr (S. Bouhallab).
} 
In general, investigations on the interactions between proteins and carotenoids have focused on protein conformational changes ( $\mathrm{Li}$, Wang, Chen, \& Lu, 2015; Mohan, Hemachandran, Sneha, Doss, \& Godwin Christopher, Jayaraman, Gurunathan, \& Ramamoorthy, Siva, 2018; Mora-Gutierrez et al., 2018; Yi, Fan, Yokoyama, Zhang, \& Zhao, 2016). Some papers reported the potential of caseinate as carotenoid nanocarrier. Mora-Gutierrez et al. (2018) assessed the interaction between caseinate from bovine and caprine milk and lutein at pH 7 and observed that the apparent solubility of lutein in the hydrophilic environment, as well as its chemical stability during storage after incorporation in emulsion-based system, improved due to the formation of casein/lutein complexes. Similar results were reported through the complex formation of lutein with whey protein isolate (WPI) or $\mathrm{NaCas}$ at $25^{\circ} \mathrm{C}$ and $\mathrm{pH} 7.4$ (Yi et al., 2016). Results also showed that lutein stability was higher in NaCas/lutein complex than in the WPI/lutein one (Yi et al., 2016). Paiva, Coelho, da Silva, Pinto, Vidigal, and Pires (2020) verified that the binding of lutein to bovine serum albumin (BSA) at $\mathrm{pH} 7.4$ was independent of the protein conformation, folded or denatured. Moreover, Allahdad, Varidi, Zadmard, and Saboury (2018) showed that $\beta$-carotene exhibited different interaction parameters with the individual casein molecules, i.e. $\beta$-, $\kappa$ - and $\alpha_{\mathrm{s}}$-casein.

Few studies concerning carotenoid-milk protein interactions took carotenoid solubility in the hydrophilic environment into consideration (Chang, Cheng, Han, Zhang, \& Skibsted, 2016; Mora-Gutierrez et al., 2018; Yi et al., 2016). In a hydrophilic environment, carotenoids are expected to exist as self-aggregated forms. The carotenoid aggregation or self-assembly in the organic-water binary solvent is a process largely driven by hydrophobic effects, being influenced by two main factors: the steric properties of the molecule structure and the attractive forces such as H-bridges, dipole forces and van der Waals interactions between neighboring molecules (Hempel, Schädle, Leptihn, Carle, \& Schweiggert, 2016). H-type and J-type carotenoid aggregates are characterized by strongly and weakly coupled aggregates, respectively (Dong, Zhang, Wang, \& Wang, 2018; Hempel et al., 2016). A recent study observed that interactions between WPI and norbixin exhibited Stern-Volmer and quenching constants with a magnitude order of $10^{4} \mathrm{M}^{-1}$ and $10^{13}$ $\mathrm{M}^{-1} \mathrm{~s}^{-1}$, respectively, independent of the carotenoid form (soluble or $\mathrm{H}$ type aggregate) (Møller et al., 2020). On the other hand, Zhu, Wang, Gao, Wu, and Sun (2019) reported that fucoxanthin aggregation affected fucoxanthin/whey protein binding. However, in general carotenoid aggregation before or after complexation with milk proteins has rarely received considerable attention.

Although some reports on the molecular interaction between caseinate or isolated casein fractions and carotenoids are available, to the best of our knowledge, the interaction between lutein and casein micelle (native phosphocaseinate) has not been investigated so far. In this context, this study aimed to assess the influence of the aggregation state of the caseins (sodium caseinate versus casein micelle) on their interaction with lutein by protein fluorescence quenching.

\section{Material and methods}

\subsection{Sample preparation}

Sodium caseinate (NaCas) (Eurial, France) and native phosphocaseinate (PPCN) (Promilk 852B, Ingredia, France) powders were used in the present study. These ingredients contained, respectively, $90.7 \pm 0.2$ and $83.1 \pm 0.4 \%(\mathrm{w} / \mathrm{w})$ protein $(\mathrm{N} \times 6.38)$, based on the total nitrogen content determined by the Kjeldahl method. The stock solution of NaCas was prepared by dispersing NaCas powder at $7.81 \mathrm{~g} \mathrm{~L}^{-1}$ (corresponding to a protein concentration of $7.08 \mathrm{~g} \mathrm{~L}^{-1}$ or $300 \mu \mathrm{M}$, considering an average molecular weight of $23.6 \mathrm{kDa}$ for individual molecules) in 10 $\mathrm{mM}$ of 4-(2-hydroxyethyl)-1-piperazine ethanesulfonic acid (Hepes) at $\mathrm{pH}$ 7. A homogeneous solution of NaCas was obtained by stirring the mixture at room temperature for $24 \mathrm{~h}$. The protein concentration of the NaCas solution was determined by UV-absorbance at $280 \mathrm{~nm}$ (spectrophotometer SAFAS UV MC2, Safas, Monaco, France) using an extinction coefficient of $0.79 \mathrm{~L} \mathrm{~g}^{-1} \mathrm{~cm}^{-1}$. This parameter was calculated considering that $\mathrm{NaCas}$ is composed of $40 \% \alpha_{\mathrm{s} 1}, 40 \% \beta, 10 \% \alpha_{\mathrm{s} 2}$ and $10 \%$ of $\kappa$-caseins, with the respective absorption coefficients of $1.01 ; 0.45$; 1.04 and $1.05 \mathrm{~L} \mathrm{~g}^{-1} \mathrm{~cm}^{-1}$ (Walstra \& Jenness, 1984). The stock solution of PPCN was prepared by dispersing PPCN powder at $8.52 \mathrm{~g} \mathrm{~L}^{-1}$ (corresponding to a protein concentration of $7.08 \mathrm{~g} \mathrm{~L}^{-1}$ ) in HEPES buffer at $\mathrm{pH}$ 7. Rehydration of PPCN powder was carried out by continuous stirring at room temperature during $10 \mathrm{~h}$ followed by heating at $40{ }^{\circ} \mathrm{C}$ for $12 \mathrm{~h}$. Afterwards, PPCN solution was kept under slow stirring at room temperature during $12 \mathrm{~h}$. Sodium azide at $0.5 \mathrm{~g} \mathrm{~L}^{-1}$ was added to both solutions to prevent microbial growth.

Lutein stock solution was prepared immediately before use by dispersing lutein powder (PHR1699, MW $568.87 \mathrm{~g} \mathrm{~mol}^{-1}$, SigmaAldrich, St. Louis, MO, USA) at $1.8 \mathrm{mM}$ in absolute ethanol or DMSO under slow stirring until complete dissolution. The absorption spectrum of lutein was obtained in a spectrophotometer (SAFAS UVmc2, Safas, Monaco, France), and the total lutein content was calculated by using the absorbance at $446 \mathrm{~nm}$ and the specific extinction coefficient of lutein in ethanol $\left(E_{1 \mathrm{~cm}}^{1 \%}=2550\right.$, corresponding to a molar absorptivity of $145,100 \mathrm{~L} \mathrm{~mol}^{-1} \mathrm{~cm}^{-1}$ ). For DMSO solution, the total lutein content was calculated by using the absorbance at $461 \mathrm{~nm}$ and the specific extinction coefficient of lutein in DMSO $\left(E_{1 \mathrm{~cm}}^{1 \%}=2369\right.$, corresponding to a molar absorptivity of $134,800 \mathrm{~L} \mathrm{~mol}^{-1} \mathrm{~cm}^{-1}$ ) (Davies, 1976).

\subsection{Protein size distribution}

Before analysis, NaCas and PPCN stock solutions were diluted 3 times (1:3) in $10 \mathrm{mM}$ Hepes buffer at $\mathrm{pH}$ 7. The influence of the addition of $5 \%(\mathrm{v} / \mathrm{v})$ ethanol or DMSO to NaCas and PPCN solutions on protein size distribution was assessed using a Zetasizer Nano Series (Malvern Instruments, Worcestershire, UK). The hydrodynamic diameter (Dh) of NaCas and PPCN at $25{ }^{\circ} \mathrm{C}$ was obtained by dynamic light scattering measurements using a backscattering angle of $173^{\circ}$. The generalpurpose model was used for experimental data analysis. The Dh was calculated according to the Stokes-Einstein equation. The mean protein size was reported as average hydrodynamic diameter $(\bar{D})$, calculated according to Eq. (1).

$\bar{D}=\sum x_{i} D_{i}$

where $x_{i}$ is the fraction of a given particle $i$ with a given scattering intensity and $\mathrm{Di}$ is the diameter of the particle $\mathrm{i}$.

\subsection{Intrinsic fluorescence}

NaCas and PPCN solutions at $1 \mu \mathrm{M}$ were obtained by diluting NaCas and PPCN stock solutions 300 times (1:300) in $10 \mathrm{mM}$ Hepes buffer at $\mathrm{pH}$ 7. From both lutein stock solutions, another solution was prepared at $170 \mu \mathrm{M}$ in absolute ethanol or DMSO. Protein intrinsic fluorescence was determined using a Safas FLX-Xenius fluorimeter (Monaco, France). The excitation wavelength was set at $280 \mathrm{~nm}$ and emission spectra were recorded between 300 and $400 \mathrm{~nm}$, using excitation and emission slit widths of $5 \mathrm{~nm}$. Diluted casein solution $(2 \mathrm{~mL})$ placed in quartz cuvette was titrated with 10 successive injections of $10 \mu \mathrm{L}$ of lutein. The lutein/ casein molar ratios ranged from 0 to 8 . The mixtures were aspired and expelled five times using a micropipette to guarantee a proper homogenization. Fluorescence measurements were taken after $15 \mathrm{~min}$ of equilibration. Ethanol and DMSO concentration in the final mixture was $5 \%$. The effect of organic solvent on the carotenoid titration curves was corrected by subtracting the protein fluorescence in presence of organic solvent from that of proteins in presence of carotenoid/organic solvent at each point of the titration. Absorption spectrum $(270-600 \mathrm{~nm})$ of the lutein/casein mixture was measured in a spectrophotometer for the correction of the inner filter effect (Lakowicz, 2006). Each titration was carried out in triplicate. 


\subsection{Isothermal titration calorimetry (ITC)}

Immediately before analysis, ethanolic lutein solution at $400 \mu \mathrm{M}$ was diluted 20 times in $10 \mathrm{mM}$ Hepes buffer at $\mathrm{pH} 7$, resulting in a lutein solution containing $5 \%(\mathrm{v} / \mathrm{v})$ ethanol. The absorption spectrum of the diluted lutein solution was measured in a spectrophotometer. Before analysis, NaCas and PPCN stock solutions were diluted 3 times (1:3) in $10 \mathrm{mM}$ Hepes buffer at $\mathrm{pH} 7$. As a control, $5 \%(\mathrm{v} / \mathrm{v})$ ethanol was added to diluted NaCas and PPCN solutions.

A VP-ITC microcalorimeter (Microcal, Northampton, MA, USA) was used to assess the binding energy of lutein to NaCas or PPCN at $25^{\circ} \mathrm{C}$. All the parameters for ITC analysis were based on those described by Velazquez-Campoy and Freire (2006). Casein solutions $(0.1 \mathrm{mM})$ and stock solutions of lutein $(0.02 \mathrm{mM})$ were degassed under vacuum before titration experiments. The reference cell was filled with $10 \mathrm{mM}$ HEPES buffer at $\mathrm{pH} 7$ with $5 \%(\mathrm{v} / \mathrm{v})$ ethanol and the sample cell $(1.425 \mathrm{~mL})$ was filled with lutein solution. Lutein solution was titrated with 29 successive injections of $10 \mu \mathrm{L}$ of casein at $100 \mu \mathrm{M}$. Each injection lasted $20 \mathrm{~s}$ with an interval of $400 \mathrm{~s}$ between consecutive injections to reach thermodynamic equilibrium. During titration, the solution in the sample cell was stirred at $300 \mathrm{rpm}$ to ensure complete homogeneity. For each ITC experiment, a reference titration was carried out by titrating casein solutions directly into $10 \mathrm{mM}$ HEPES buffer with $5 \%(\mathrm{v} / \mathrm{v})$ ethanol. The casein dilution data (reference experiment) were subtracted from casein/lutein binding experimental data using the Origin 7.0 software. The area under each injection peak was plotted as a function of the casein/lutein molar ratio.

\section{Results}

\subsection{Lutein aggregates in organic-aqueous system}

Most carotenoids are not water-soluble but may be dissolved by cosolvents (Chang et al., 2016) such as ethanol and DMSO. Carotenoids form aggregates in a hydrophilic environment due to their highly hydrophobic character (Dong et al., 2018; Hempel et al., 2016), as shown after comparing the lutein absorption spectra in a pure organic solvent and $10 \mathrm{mM}$ Hepes buffer at $\mathrm{pH} 7$ (Fig. $1 \mathrm{~A}$ and B). The UV/vis spectrum of lutein in pure DMSO showed absorption maxima at 435, 461, and 491 $\mathrm{nm}$, while the dissolved state of lutein in pure ethanol showed absorption maxima at 421, 446 and $474 \mathrm{~nm}$, as expected. Upon aqueous dilution, loss of vibrational fine structure, large hypsochromic shift, and hypochromic effect were observed for both organic-aqueous systems. These solvent-induced changes in absorption characterize the formation of H-type aggregates (Dong et al., 2018; Hempel et al., 2016). Free hydroxyl groups at both ends of the lutein molecule promoted the formation of strongly coupled (H-type) aggregates due to the formation of intermolecular hydrogen bonds (Hempel et al., 2016). Also, the almost complete disappearance of the initial monomer bands indicates that, after dilution in a buffer, lutein is mostly present in the aggregate form instead of dispersed molecules. Consequently, in aqueous solution, the interaction of lutein with macromolecules involves at least in part its aggregated forms, a fact that it is not always specified in the published studies.

\subsection{Low volume of organic solvent does not affect the protein size distribution}

The solutions of NaCas and PPCN in buffer presented bimodal and monomodal particle size distribution, respectively (Fig. 2). The average Dh of PPCN solution was about $200 \mathrm{~nm}$. On the other hand, the major size peak of NaCas solution exhibited the average hydrodynamic diameter around $20 \mathrm{~nm}$. As expected, the average hydrodynamic diameter of PPCN was 10-fold higher than that observed for NaCas in aqueous solution (Casanova et al., 2018; Pan et al., 2013). This result is directly related to the highest content of colloidal calcium-phosphate in PPCN which plays an important role in casein micelle stabilization. The addition of ethanol ( $5 \% \mathrm{v} / \mathrm{v})$ did not significantly affect the observed protein size distribution. Similar results were also observed in the presence of $5 \%(\mathrm{v} / \mathrm{v})$ DMSO (data not shown).

\subsection{Lutein binds to one binding site on NaCas and PPCN}

Fig. 3 shows the UV-vis absorption spectra of the NaCas and PPCN solutions in HEPES buffer at $\mathrm{pH} 7$ in the absence and presence of increasing concentrations of lutein (lutein/protein molar ratios from 0 to $8 \mu \mathrm{M}$ ). Casein/lutein mixture resulted in an absorption peak with an absorption maximum at $384 \mathrm{~nm}$, typical of H-type aggregates of lutein. Thus, it is worth noting that although lutein was added to casein in a dispersed form (monomers), the absorption spectra show that lutein aggregates (H-type) are present after lutein addition to NaCas and PPCN buffer solutions. The casein/lutein absorption intensity increased linearly by increasing lutein concentration (Chang et al., 2016; Yi et al., 2016), while the profile of the absorption spectra did not change after lutein additions. A linear concentration dependent absorbance in agreement with the Beer - Lambert law indicates that a homogeneous solution was formed for $0-8 \mu \mathrm{M}$ lutein in buffer solution of NaCas or PPCN with 5\% (v/v) of ethanol or DMSO (Chang et al., 2016). Control experiments in the absence of casein (lutein in buffer) showed absorption intensities $25 \%$ lower than those values observed for casein/lutein (data not shown). Similar results were also observed in the presence of $5 \%(\mathrm{v} / \mathrm{v})$ DMSO (data not shown).

The inner-filter effect distorts the fluorescence data since an absorbing compound added to a solution tends to reduce the number of excitation radiations that reach the fluorophore or absorb some of the radiations emitted by the fluorophore (Lakowicz, 2006; van de Weert, 2010). As the absorbance of the added ligand at the excitation (data not shown) and/or emission wavelength is above 0.1 at lutein concentration
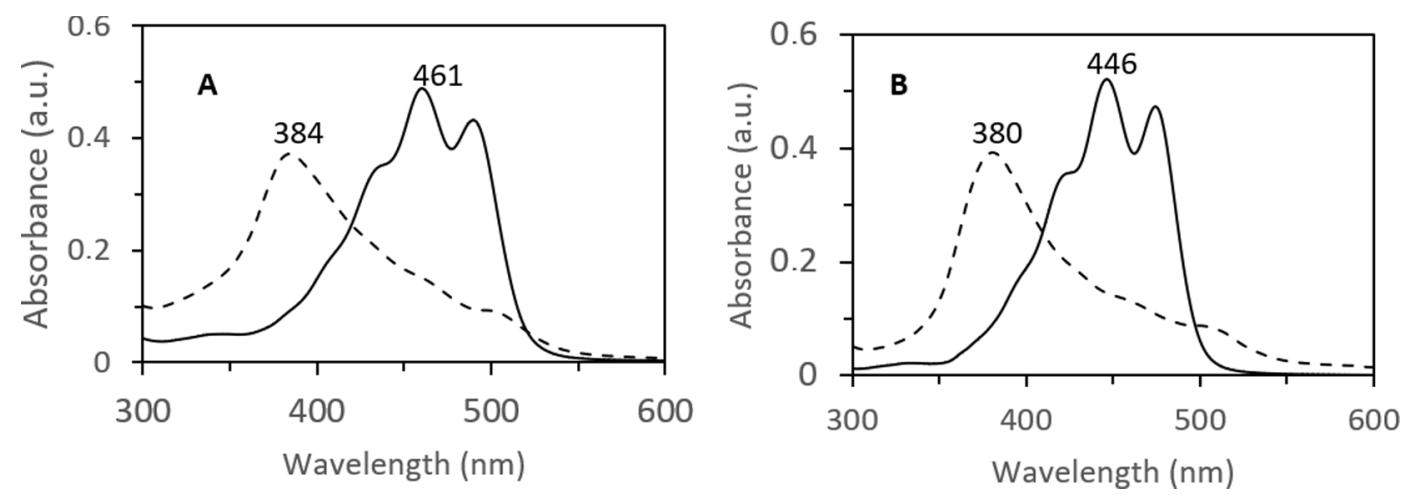

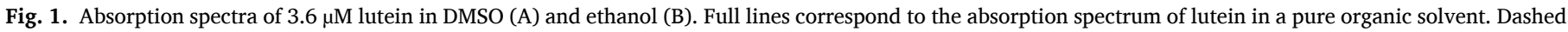
lines correspond to the absorption spectrum of lutein in $10 \mathrm{mM}$ Hepes buffer at $\mathrm{pH} 7$ containing $5 \%$ ( $/ \mathrm{v}$ ) of organic solvent. 

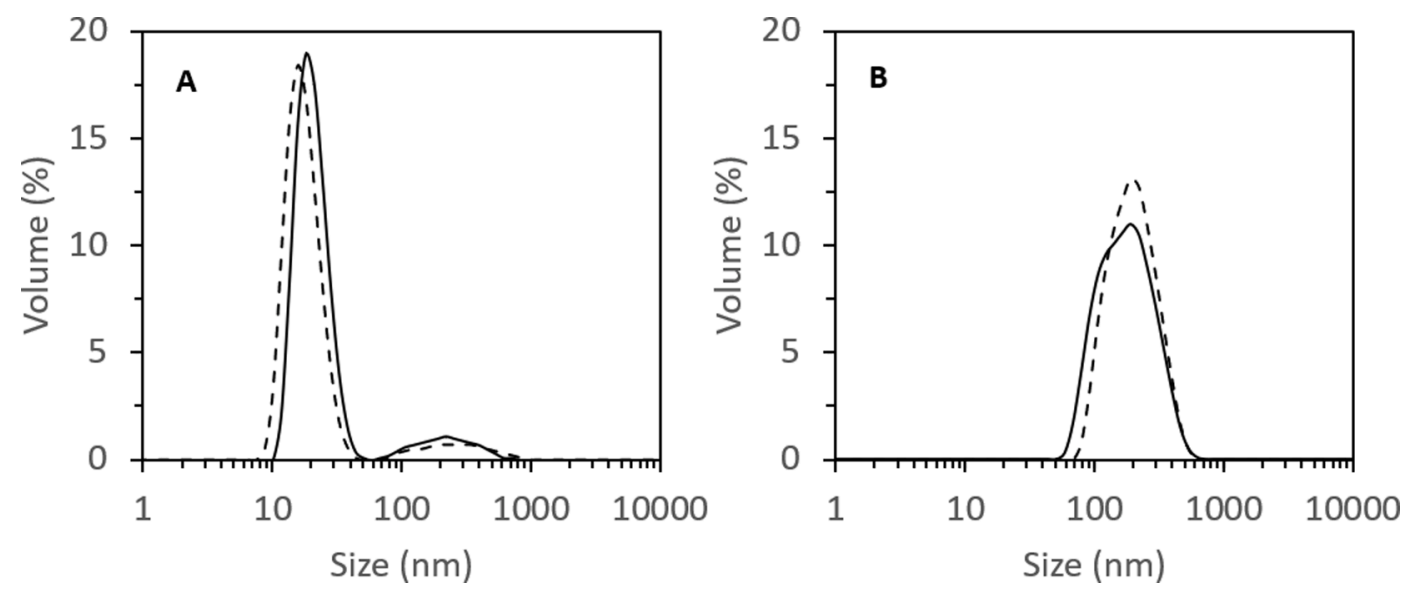

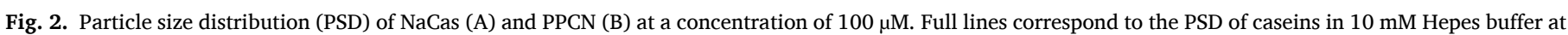
$\mathrm{pH}$ 7. Dashed lines correspond to the PSD of caseins in $10 \mathrm{mM}$ Hepes buffer at $\mathrm{pH} 7$ containing $5 \%$ (v/v) ethanol.
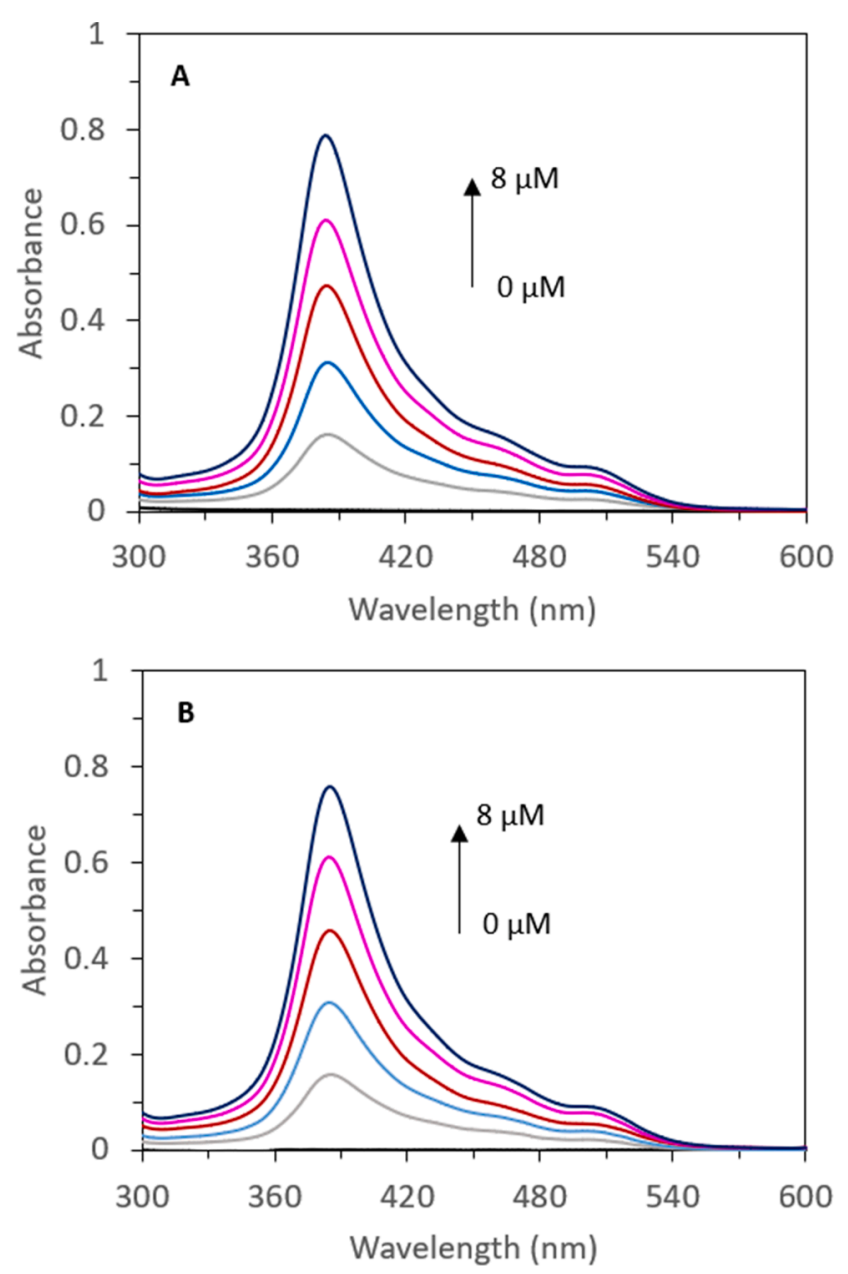

Fig. 3. Interaction between caseins $(1 \mu \mathrm{M})$ and lutein in the presence of ethanol. Absorption spectra of $1 \mu \mathrm{M}$ NaCas (A) and PPCN (B) at $\mathrm{pH} 7$ in the absence and presence of an increasing concentration of lutein in ethanol (from 0 to $8 \mu \mathrm{M})$.

of 4-8 $\mu \mathrm{M}$, the observed fluorescence intensities were corrected to avoid the inner-filter effect according to Eq. (2) (Lakowicz, 2006).

$F_{\text {corr }}=F_{\text {obs }} \times 10^{\frac{A e x c+A e m}{2}}$

where $\mathrm{F}_{\text {corr }}$ is the corrected fluorescence value, $F_{\text {obs }}$ the measured fluorescence value, $\mathrm{A}_{\mathrm{exc}}$, and $\mathrm{A}_{\mathrm{em}}$ the absorption values at the excitation and emission wavelengths, respectively, determined in a $1 \mathrm{~cm}$ cuvette.

Protein fluorescence is mainly due to tryptophan residues (Trp) when excited at $280 \mathrm{~nm}$. In bovine milk, both $\alpha_{\mathrm{s} 1}$-casein and $\alpha_{\mathrm{s} 2}$-casein have 2 Trp residues while $\beta$-casein and $\kappa$-casein have 1 Trp residue each (Yi et al., 2016). Thus, casein fluorescence results from a combination of fluorophores located on different protein molecules. Ligand binding in regions near the fluorophores induces changes in the local environment and consequently in fluorescence intensity, proportionally to added ligand concentration.

Fig. 4 presents the typical fluorescence emission spectra of NaCas and PPCN solutions at $\mathrm{pH} 7$ in the absence and presence of increasing concentrations of lutein (lutein/protein molar ratios from 0 to $8 \mu \mathrm{M}$ ). After excitation at $280 \mathrm{~nm}$, the maximum emission wavelength of NaCas and PPCN was recorded around $334 \mathrm{~nm}$. Trp residues are likely placed in the supramolecular structure core when dispersed in a hydrophilic environment due to their hydrophobic character. The maximum emission wavelengths of NaCas and PPCN presented a blue shift of about 30 $\mathrm{nm}$ when compared to free Trp in water (Teale \& Weber, 1957), which corroborates the hypothesis that Trp residues were buried. Organic solvents can affect protein structure (Lakowicz, 2006), for instance, at high concentrations, ethanol may promote casein aggregation (Celli, Lawrence, Ravanfar, \& Abbaspourrad, 2019). On the other hand, the presence of ethanol and DMSO at low concentration $(5 \% \mathrm{v} / \mathrm{v})$ practically did not affect the size of the different casein supramolecular structures (Fig. 2). Conversely, the fluorescence intensity of caseins decreased in $20 \%$ even at low concentration of organic solvents (data not shown) suggesting changes in the microenvironment surrounding the Trp residues such as protein rearrangements (Celli et al., 2019).

The wavelength of maximum fluorescence intensity did not change after lutein addition in the presence of ethanol (Fig. 4), consistent with a previous study (Yi et al., 2016). This fact shows that lutein-casein interaction did not affect the microenvironment of Trp residues in NaCas and PPCN. In the presence of DMSO, a slight blue shift of this maximum wavelength was observed with increasing lutein concentration. This hypsochromic shift in DMSO suggests the presence of two populations of fluorophores, indicating that the Trp residues emitting at larger wavelengths are quenched more readily than the Trp emitting at shorter wavelength (Lakowicz, 2006). The fluorescence intensity of NaCas and PPCN gradually decreased (quenching mechanism) with increasing lutein concentration and a tendency to reach a plateau value was observed, regardless of the organic solvent used to prepare the lutein stock solution (DMSO or ethanol).

The fluorescence quenching data were analyzed according to SternVolmer (Eq. (3)). 

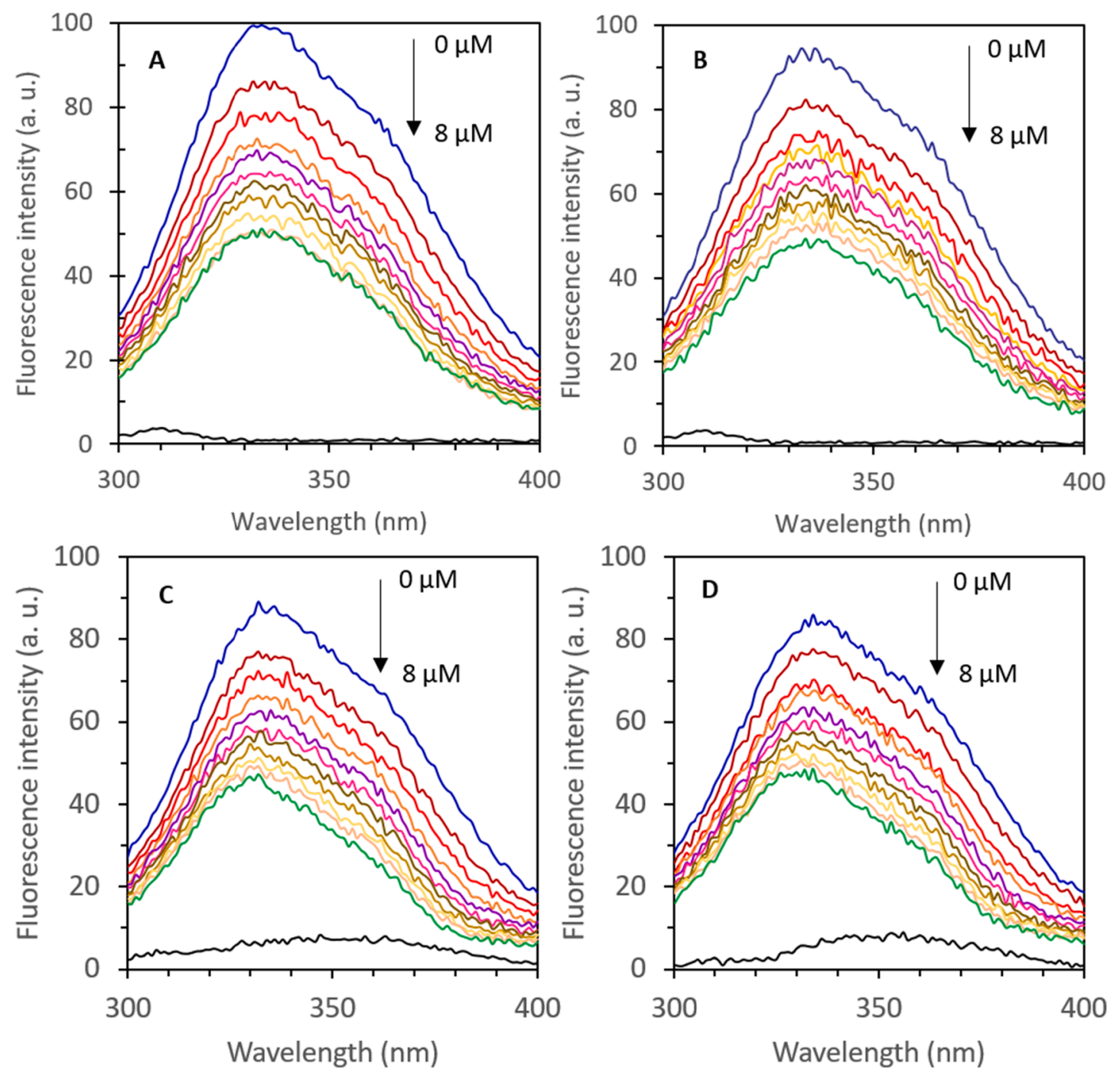

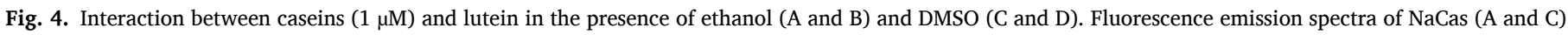

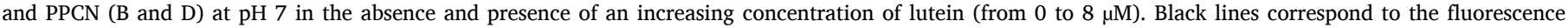
spectrum of lutein $8 \mu \mathrm{M}$ in Hepes buffer containing $5 \%(\mathrm{v} / \mathrm{v})$ ethanol or DMSO.

$\frac{F_{0}}{F}=1+k_{q} \tau_{0}[Q]=1+K_{S V}[Q]$

where $\mathrm{F}_{0}$ and $\mathrm{F}$ are fluorescence intensities in the absence and presence of quencher, respectively, $k_{\mathrm{q}}$ is the bimolecular quenching constant, $\tau_{0}$ is the lifetime of the fluorophore in the absence of quencher ( $\tau_{0}$ value for Trp residue is $10^{-8} \mathrm{~s}$ according to Lakowicz (2006)), [Q] is the total concentration of quencher, and $\mathrm{K}_{\mathrm{SV}}$ is the Stern-Volmer quenching constant. Moreover, to confirm the number of sets of fluorophore populations of casein, as well as their accessibility to lutein, the fluorescence quenching data was also analyzed according to the modified SternVolmer equation (Eq. (4)).

$\frac{F_{0}}{F_{0}-F}=\frac{1}{f_{a} K_{S V}[Q]}+\frac{1}{f_{a}}$

where $f_{a}$ is the fraction of the initial fluorescence that is accessible to quencher and $\mathrm{K}_{\mathrm{SV}}$ is the effective quenching constant for the accessible fluorophore. The modified form of the Stern-Volmer equation allows $f_{a}$ and $K_{S V}$ to be determined graphically from $y$-intercept, $1 / f_{a}$ (by extrapolation), and slope, $1 /\left(\mathrm{f}_{\mathrm{a}} \mathrm{K}_{\mathrm{SV}}\right)$. Fluorescence quenching data of ligand/protein binding are usually fitted according to Stern-Volmer equations. Gheonea, Aprodu, Râpeanu, and Stănciuc (2018) reported a linear modified Stern-Volmer plot and $\mathrm{f}_{\mathrm{a}}<1.0$ for lycopene extract $/ \beta$-lg binding, suggesting unequal accessibility of lycopene to two populations of Trp. Linear modified Stern-Volmer plots were also observed in previous studies of binding between bixin/whey proteins and norbixin/ whey proteins or norbixin/NaCas (Zhang \& Zhong, 2012a, 2012b, 2013).

Fig. 5A-D show the Stern-Volmer plots of the fluorescence quenching of NaCas and PPCN in the presence of ethanol. The binding parameters are given in Table 1 . The fluorescence ratio $\mathrm{F}_{0} /\left(\mathrm{F}_{0}-\mathrm{F}\right)$ versus $1 /[\mathrm{Q}]$ for casein/lutein presented a linear evolution of both Stern-Volmer and modified Stern-Volmer plots and the fraction accessible to quencher $\left(f_{a}\right)$ was lower than 1.0, which is typical of two populations of Trp on casein fractions composing both casein supramolecular structures at $\mathrm{pH} 7$, one accessible to the quencher and the other inaccessible (Lakowicz, 2006). This binding complexity is expected since NaCas and PPCN are composed of different fractions of casein molecules (Casanova et al., 2018), i.e., they are not isolated casein fractions. The $f_{a}$ values ranged from 0.57 to 0.69 , meaning that 60 to $70 \%$ of the initial fluorophores in casein molecules are accessible for lutein binding. The values of $\mathrm{K}_{\mathrm{SV}}$ determined from the linear evolution of the Stern-Volmer plots presented a magnitude order of $10^{5} \mathrm{M}^{-1}$.

Fluorescence quenching can be a consequence of static and/or dynamic mechanisms. The dynamic quenching is caused by collisional encounters between the fluorophore and the quencher. Conversely, the 

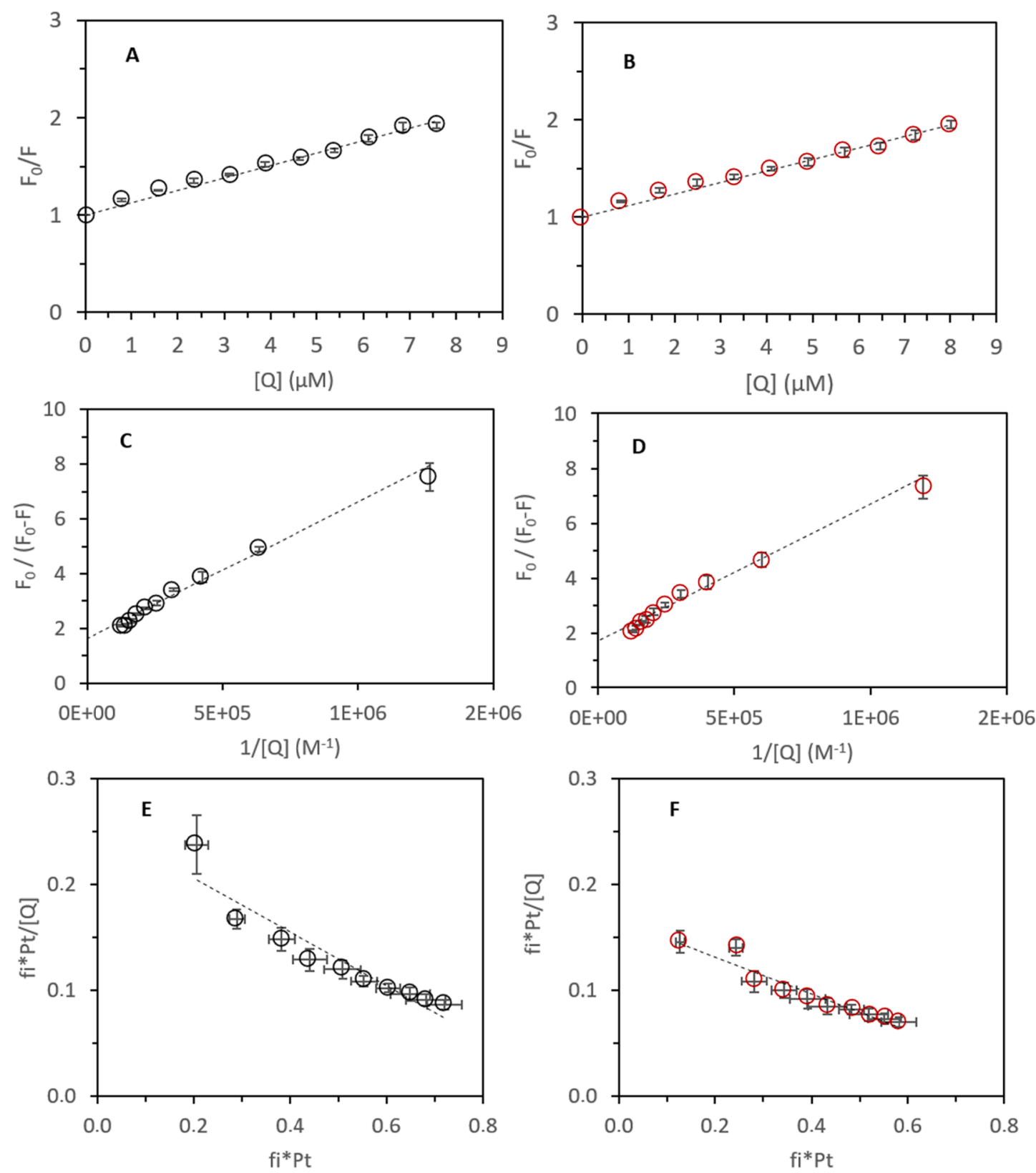

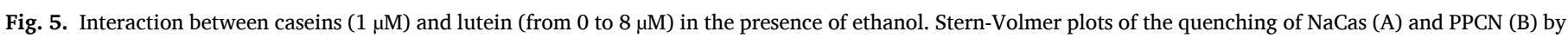

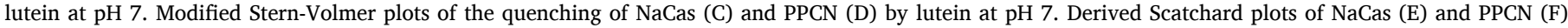
quenching by lutein at $\mathrm{pH}$.

formation of a ground-state complex between them is classified as static quenching (Lakowicz, 2006). According to the correspondence $\mathrm{K}_{\mathrm{SV}}=$ $\mathrm{k}_{\mathrm{q}} \tau_{0}$ in Eq. (1), the values of $k_{\mathrm{q}}$ for both caseins had a magnitude order of $10^{13} \mathrm{M}^{-1} \mathrm{~s}^{-1}$, which is higher than the typical diffusion-controlled limit $\left(\sim 10^{10} \mathrm{M}^{-1} \mathrm{~s}^{-1}\right)$. These values indicate that the quenching of NaCas and PPCN fluorescence by lutein followed a static mechanism (Lakowicz, 2006). The static mechanism of fluorescence quenching seems to be quite widespread since it was also reported for the interactions between lutein and caseinate or whey proteins or bovine serum albumin (Paiva et al., 2020; Yi et al., 2016).

The quenching of casein fluorescence by lutein was analyzed according to the Scatchard representation (Eq. (5)) to better characterize the casein/lutein interaction (Scatchard, 1949). The equilibrium binding constant, $\mathrm{K}_{\mathrm{b}}$, was determined from the slope of the plot of $\left(\mathrm{f}_{\mathrm{i}} \times \mathrm{P}_{\mathrm{T}}\right)$ / [Q] versus $\left(f_{i} \times P_{T}\right)$. $P_{T}$ represents total protein concentration, and $f_{i}$ is the fraction of protein fluorescence that can be quenched by the ligand; it is directly proportional to the fraction of protein binding sites occupied by the ligand. The $\mathrm{f}_{\mathrm{i}}$ value was calculated according to the following equation (Eq. (6)).

$f_{i} \frac{\left[P_{t}\right]}{[Q]}=n K_{b}\left[P_{t}\right]-K_{b} f_{i}\left[P_{t}\right]$

$f_{i}=\frac{F-F_{0}}{F_{\infty}-F_{0}}$

where $F_{\infty}$ is fluorescence intensity value at saturation.

Fig. 5E and 5F show the Scatchard plots of NaCas/lutein and PPCN/ lutein interactions in the presence of ethanol. A linear Scatchard plot typical of one class of binding sites was observed for lutein binding to both casein structures. The binding constant of casein/lutein complexation presented a magnitude order of $10^{5} \mathrm{M}^{-1}$, whatever the casein supramolecular structure. This result reflects a moderate affinity 
Table 1

Binding parameters of casein/lutein in the presence of ethanol and DMSO. ${ }^{\mathrm{a}, *}$

\begin{tabular}{llllll}
\hline Solvent & Casein & $\mathrm{f}_{\mathrm{a}}{ }^{\mathrm{b}}$ & $\mathrm{K}_{\mathrm{SV}}{ }^{\mathrm{b}}$ & $k_{\mathrm{q}}{ }^{\mathrm{b}}$ & $\mathrm{K}_{\mathrm{b}}{ }^{\mathrm{c}}$ \\
\hline \multirow{6}{*}{ DMSO } & & $(-)$ & $\left(\times 10^{5}\right.$ & $\left(\times 10^{13}\right.$ & $\left(\times 10^{5} \mathrm{M}^{-1}\right)$ \\
& & & $\left.\mathrm{M}^{-1}\right)$ & $\left.\mathrm{M}^{-1} \mathrm{~s}^{-1}\right)$ & \\
& NaCas & $0.57 \pm 0.03$ & $3.4 \pm 0.5$ & $3.3 \pm 0.5$ & $2.52 \pm 0.25$ \\
& PPCN & $0.69 \pm 0.04$ & $1.8 \pm 0.2$ & $1.8 \pm 0.2$ & $1.61 \pm 0.24$ \\
& NaCas & $0.62 \pm 0.05$ & $3.6 \pm 0.8$ & $3.6 \pm 0.8$ & $2.70 \pm 0.26$ \\
& PPCN & $0.59 \pm 0.02$ & $3.4 \pm 0.1$ & $3.4 \pm 0.1$ & $2.84 \pm 0.36$ \\
\hline
\end{tabular}

* Fluorescence quenching titration of casein solutions $(1 \mu \mathrm{M})$ was carried out by increasing lutein concentration (from 0 to $8 \mu \mathrm{M}$ ).

${ }^{\text {a }}$ Mean and standard deviation of three replicates $(n=3)$.

b Parameters calculated by data fitting of casein/lutein fluorescence quenching according to Stern-Volmer and modified Stern-Volmer equations (Lakowicz, 2006).

c Parameter calculated by data fitting of casein/lutein fluorescence quenching according to Scatchard representation (Scatchard, 1949).

between casein and lutein, similarly to that previously reported about the interaction between lutein and whey protein or sodium caseinate (Yi et al., 2016) and lutein/human serum albumin (Chen et al., 2018). The $\mathrm{K}_{\mathrm{b}}$ is also in the same magnitude order of that found for the interaction between casein micelles and hydrophobic compounds such as curcumin (Khanji et al., 2015; Rahimi Yazdi \& Corredig, 2012). On the other hand, Paiva et al. (2020) reported a magnitude order of binding constant 10fold lower for BSA/lutein complexation. Altogether, this information suggests that NaCas and PPCN have a higher affinity with lutein than BSA.

The data of fluorescence quenching for casein/lutein interaction in the presence of DMSO were also fitted according to Stern-Volmer, modified Stern-Volmer and Scatchard representation (see Fig. 1S, Supporting Information), as described above. The results observed for fluorescence quenching in the presence of DMSO were in the same order of magnitude for those observed in the presence of ethanol (Table 1). Thus, the magnitude order of the $\mathrm{K}_{\mathrm{b}}$ was not influenced by the supramolecular structure of casein or the organic solvent (ethanol or DMSO).
It means that both NaCas and PPCN presented similar affinity with lutein.

ITC enables the determination of the thermodynamic parameters of the interaction between protein and ligand. Preliminary assays were carried out by injecting lutein into casein solution, since most of the studies on ligand/protein binding usually place ligand and protein in the syringe and cell, respectively (Casanova et al., 2018; Zhang, Wright, \& Zhong, 2013; Zhang \& Zhong, 2012a). However, the high concentration of lutein in buffer with low content of organic solvent led to fast phase separation due to the formation of big aggregates of lutein. To avoid the destabilization of lutein solution during ITC analysis, a reverse titration was conducted as recommended by Velazquez-Campoy and Freire (2006). It means that the less-soluble reactant (lutein) was placed in the sample cell. To the best of our knowledge, this is the first study conducting reverse ITC to investigate interactions between milk proteins and carotenoids despite the very low solubility of the latter in the presence of high content of water.

Fig. 6 shows the raw signal of isothermal calorimetric titration obtained from the injection of NaCas and PPCN into an aqueous dispersion of lutein $(20 \mathrm{mM})$ containing $5 \%(\mathrm{v} / \mathrm{v})$ of ethanol. Heat change associated with a single injection of NaCas and PPCN into lutein solution is represented by each peak. The injections of NaCas and PPCN into an aqueous dispersion of lutein resulted in exothermic peaks, consistent with bixin/whey protein binding (Zhang et al., 2013; Zhang \& Zhong, 2012a). The energy contribution of casein dilution assessed by injection of the NaCas and PPCN solutions into the buffer containing 5\% (v/v) of ethanol (see Fig. 2S, Supporting Information) practically did not differ when compared to the heat exchange associated with the lutein/casein binding. Similar results were also observed in the presence of DMSO (data not shown). It is worth emphasizing that the ITC profiles obtained from NaCas and PPCN dilution shown in Fig. 2S (Supporting Information) were very different. The heat effect associated with NaCas dilution was negligible (flat isotherm), whilst the PPCN dilution exhibited a profile similar to that classically obtained for ligand/protein binding that is characterized by a continuous decrease in heat released until a
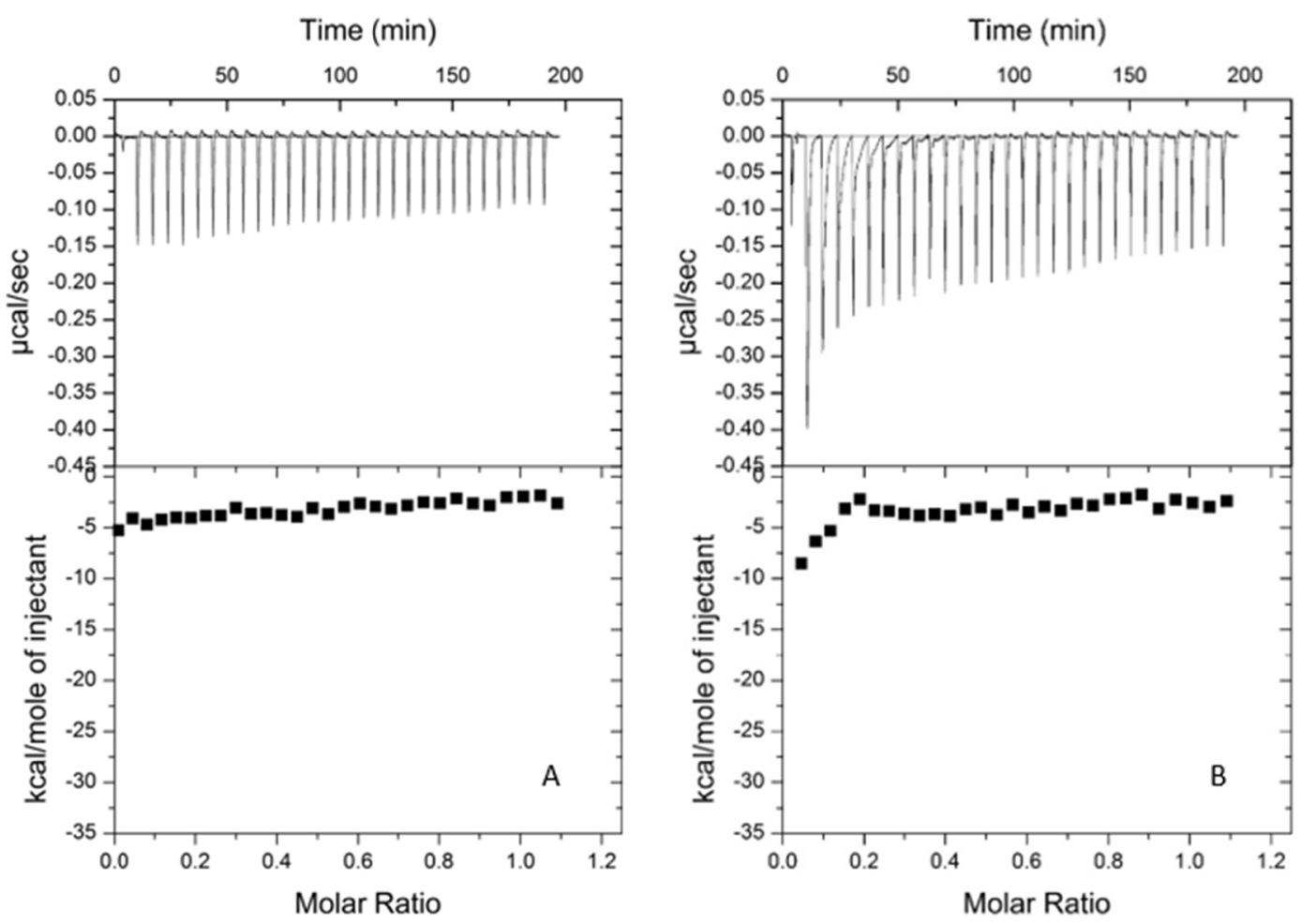

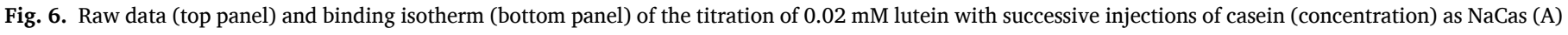
or PPCN (B). The experiments were carried out at $25^{\circ} \mathrm{C}$ in $10 \mathrm{mM}$ Hepes buffer, pH 7.0, with 5\% (v/v) ethanol. 
constant enthalpic value. It is known that PPCN has a much higher content of colloidal calcium-phosphate than NaCas. Then, a buffer saturated with calcium phosphate was used to evaluate the influence of this mineral on the isotherm of PPCN dilution. The injections of PPCN solution into the buffer, both saturated with calcium phosphate, resulted in much lower heat exchange (see Fig. 3S, Supporting Information) than that observed using a buffer without calcium phosphate (Fig. 2S-B, Supporting Information). This result confirmed that a large heat of PPCN dilution observed using a buffer without calcium phosphate was due to the release of calcium phosphate nano-clusters from casein micelle.

As the ITC profiles (Fig. 6) did not present a tendency of saturation of the binding sites, it was not possible to thermodynamically characterize lutein/casein interaction using such technique. Previous studies successfully confirmed by fluorescence quenching and ITC that the binding process of bixin and whey proteins was mainly driven by hydrophobic interactions (Zhang et al., 2013; Zhang \& Zhong, 2012a). Bixin is a carotenoid with a free carboxyl end group and another esterified carboxyl end group (Mercadante, 2007). Despite being both xanthophylls, bixin differs significantly from lutein structure. It was likely the reason why a wide range of bixin/protein molar ratio could be studied, resulting in a tendency of saturation of protein binding sites. It is important to highlight that differently from the fluorescence quenching assays, a stock solution of lutein in a buffer (aggregated form) was used for ITC analysis instead of an ethanolic stock solution (dispersed form). Zhu et al. (2019) investigated the interaction between whey protein and fucoxanthin (FX) as monomers or aggregates by injecting FX dispersed in ethanol or 1:4 ethanol/water, respectively, into protein solution. Nevertheless, the absorption spectra of lutein/casein complexes in buffer showed the presence of lutein aggregates (H-type) even though lutein was directly added to casein solutions as monomers (Fig. 3). This suggests that under these conditions, casein particles interact with the aggregated forms of lutein, consistent with $\beta$-carotene/BSA binding (Chang et al., 2016). Consequently, we propose the following scheme (Fig. 7) to describe casein/lutein interaction in mixed water/solvent solution: aggregation of lutein molecules immediately occurs once injected into a buffer solution containing caseins, before their interaction with casein. Hence, as the aggregation constant (k1) is probably faster than the interaction constant $(\mathrm{k} 2)$, the major part of the formed complexes involved casein-aggregated lutein. The presence of a small part of casein/lutein monomer complex is not excluded; its proportion depends on the solubility limit of lutein in the organic solvent/water mixture. This scheme allows us to suggest that particular attention should be paid to the interpretation of data on molecular interactions involving low-water-soluble hydrophobic ligands.

\section{Conclusion}

Fluorescence quenching results suggest that lutein binds to one set of binding sites on NaCas and PPCN in ethanol-aqueous or DMSO-aqueous solutions. Lutein/casein complexation is mainly driven by hydrophobic interactions with binding constant of a magnitude order of $10^{5} \mathrm{M}^{-1}$, independently of the supramolecular casein structure. Considering that casein-lutein interaction is not affected by casein supramolecular structure, PPCN arises as a potential nanocarrier for new lutein-rich functional foods, mainly for the elderly since PPCN is also a natural delivery system of calcium. The understanding of the mechanism of interaction between food proteins and carotenoids constitutes the preliminary step in designing efficient protein-based and functional systems for carotenoid delivery. However, further studies on the effect of the supramolecular structure of casein on chemical stability and bioaccessibility of lutein in complex systems are needed to confirm such potential application.

\section{CRediT authorship contribution statement}

Raphaela Araujo Mantovani: Conceptualization, Validation, Formal analysis, Investigation, Writing - original draft. Pascaline Hamon: Methodology, Validation, Investigation. Florence Rousseau: Methodology, Validation, Investigation. Guilherme M. Tavares: Conceptualization, Supervision, Writing - review \& editing, Funding

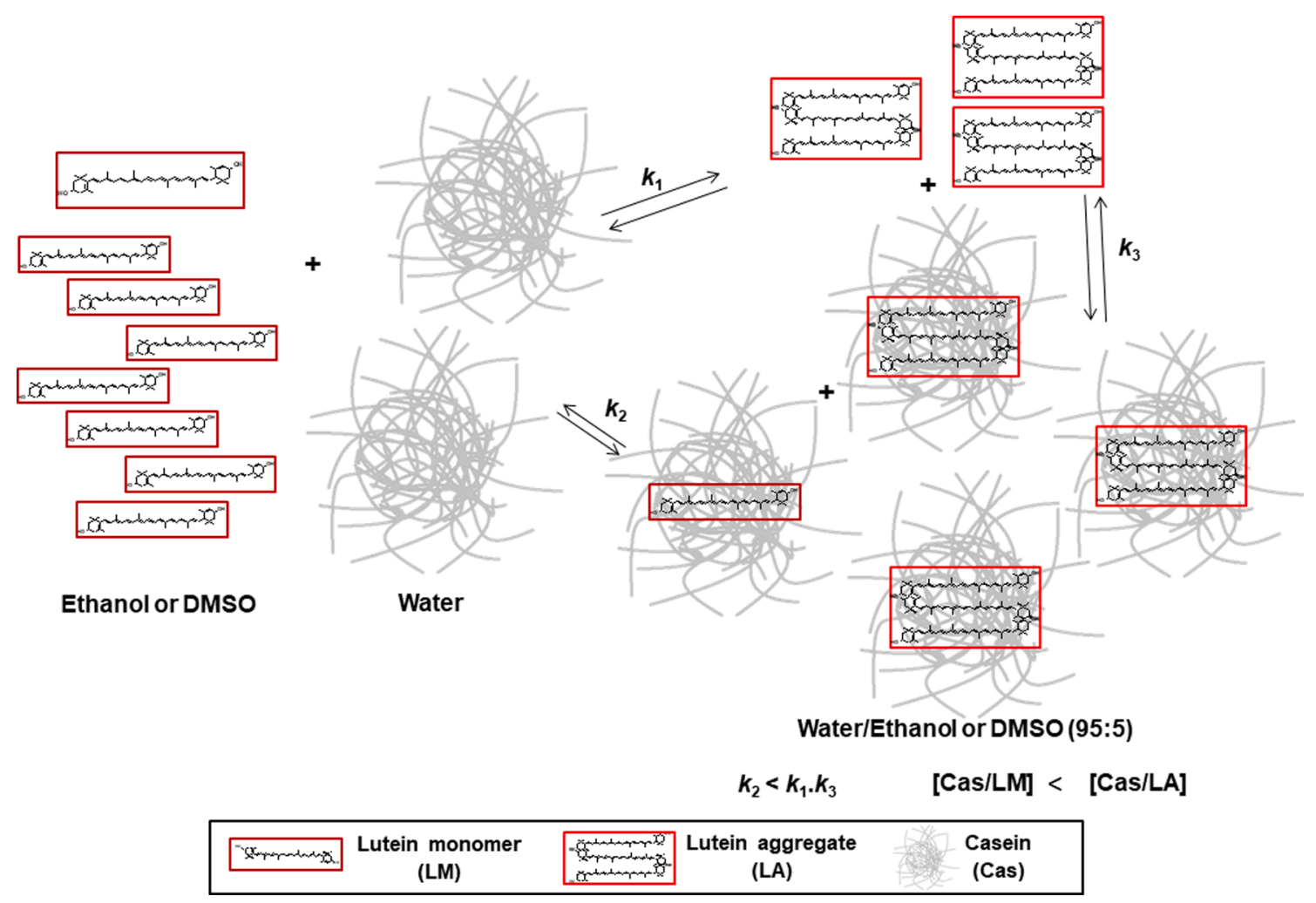

Fig. 7. Scheme of lutein aggregation versus lutein/casein binding. 
acquisition. Adriana Zerlotti Mercadante: Conceptualization, Supervision, Resources, Writing - review \& editing, Funding acquisition. Thomas Croguennec: Conceptualization, Supervision, Resources, Project administration, Writing - review \& editing. Saïd Bouhallab: Conceptualization, Supervision, Resources, Project administration, Writing - review \& editing, Conceptualization, Supervision, Resources, Project administration, Writing - review \& editing.

\section{Declaration of Competing Interest}

The authors declare that they have no known competing financial interests or personal relationships that could have appeared to influence the work reported in this paper.

\section{Acknowledgments}

We are grateful for the financial support from the São Paulo Research Foundation (FAPESP) (grants 2013/07914-8, 2017/09214-4, 2017/ 26237-8, 2018/18374-8) and INRAE France. AZM also thanks CNPq (grant 309182/2018-2).

\section{Appendix A. Supplementary data}

Supplementary data to this article can be found online at https://doi. org/10.1016/j.foodres.2020.109781.

\section{References}

Allahdad, Zahra, Varidi, Mehdi, Zadmard, Reza, \& Saboury, Ali Akbar (2018) Spectroscopic and docking studies on the interaction between caseins and $\beta$-carotene. Food Chemistry, 255, 187-196. https://doi.org/10.1016/j. foodchem.2018.01.143.

Broyard, Camille, \& Gaucheron, Frédéric (2015). Modifications of structures and functions of caseins: A scientific and technological challenge. Dairy Science \& Technology, 95(6), 831-862. https://doi.org/10.1007/s13594-015-0220-y.

Casanova, Federico, Chapeau, Anne-Laure, Hamon, Pascaline, de Carvalho, Antonio F., Croguennec, Thomas, \& Bouhallab, Saïd (2018). pH- and ionic strength-dependent interaction between cyanidin-3-O-glucoside and sodium caseinate. Food Chemistry, 267, 52-59. https://doi.org/10.1016/j.foodchem.2017.06.081.

Celli, Giovana B., Lawrence, Peter, Ravanfar, Raheleh, \& Abbaspourrad, Alireza (2019). Solvent-mediated pressure-treated bixin-casein complexation for targeted color delivery. Food Chemistry, 278, 434-442. https://doi.org/10.1016/j. foodchem.2018.11.083.

Chang, Hui-Ting, Cheng, Hong, Han, Rui-Min, Zhang, Jian-Ping, \& Skibsted, Leif H. (2016). Binding to Bovine Serum Albumin Protects $\beta$-Carotene against Oxidative Degradation. Journal of Agricultural and Food Chemistry, 64(29), 5951-5957. https:// doi.org/10.1021/acs.jafc.6b02436.

Chen, Yashu, Zhou, Yufeng, Chen, Mo, Xie, Bijun, Yang, Jifang, Chen, Jigang, \& Sun, Zhida (2018). Isorenieratene interaction with human serum albumin: Multispectroscopic analyses and docking simulation. Food Chemistry, 258, 393-399. https://doi.org/10.1016/j.foodchem.2018.02.105.

Davies, B. H. (1976) Chemistry and Biochemistry of Plant Pigments (Vol. 2). London: Academic Press.

Dong, Jia, Zhang, Di, Wang, Xin-Yue, \& Wang, Peng (2018). Solvent tuning configurational conversion of lycopene aggregates in organic-aqueous mixing solvent. Chemical Physics Letters, 701, 52-57. https://doi.org/10.1016/j. cplett.2018.04.033.

Gheonea, Ionica, Aprodu, Iuliana, Râpeanu, Gabriela, \& Stănciuc, Nicoleta (2018). Binding mechanisms between lycopene extracted from tomato peels and bovine $\beta$-lactoglobulin. Journal of Luminescence, 203, 582-589. https://doi.org/10.1016/j. jlumin.2018.07.017.

Hempel, Judith, Schädle, Christopher N., Leptihn, Sebastian, Carle, Reinhold, \& Schweiggert, Ralf M. (2016). Structure related aggregation behavior of carotenoids and carotenoid esters. Journal of Photochemistry and Photobiology A: Chemistry, 317, 161-174. https://doi.org/10.1016/j.jphotochem.2015.10.024.

Khanji, Aya N., Michaux, Florentin, Jasniewski, Jordane, Petit, Jeremy, Lahimer, Emna, Cherif, Mohamed, ... Banon, Sylvie (2015). Structure and gelation properties of casein micelles doped with curcumin under acidic conditions. Food \& Function, 6 (12), 3624-3633. https://doi.org/10.1039/C5FO00829H.

Lakowicz, J. R. (2006). Principles of fluorescence spectroscopy. New York: Springer.

Li, Xiangrong, Wang, Gongke, Chen, Dejun, \& Lu, Yan (2015). $\beta$-Carotene and astaxanthin with human and bovine serum albumins. Food Chemistry, 179, 213-221. https://doi.org/10.1016/j.foodchem.2015.01.133.

Mercadante, A. Z. (2007). Carotenoids in foods: Sources and stability during processing and storage. In C. Socaciu (Ed.), Food colorants chemical and functional properties (pp. 213-240). Boca Raton, FL, USA: CRC Press (Taylor and Francis Group).

Mohan, Sankari, Hemachandran, Hridya, Sneha, P., George Priya Doss, C., Godwin Christopher, J., Jayaraman, Gurunathan, \& Ramamoorthy, Siva. (2018). Structural insights into the binding mode and conformational changes of BSA induced by bixin and crocin. Journal of Biomolecular Structure and Dynamics, 36(8), 2085-2098. http://doi.org/10.1080/07391102.2017.1342565.

Møller, Anders Hauer, Wijaya, Wahyu, Jahangiri, Amita, Madsen, Bjoern, Joernsgaard, Bjarne, Vaerbak, Signe, ... Dalsgaard, Trine Kastrup (2020). Norbixin binding to whey protein isolate - alginate electrostatic complexes increases its solubility and stability. Food Hydrocolloids, 101, Article 105559. https://doi.org/ 10.1016/j.foodhyd.2019.105559.

Mora-Gutierrez, A., Attaie, R., Núñez de González, M. T., Jung, Y., Woldesenbet, S., \& Marquez, S. A. (2018). Complexes of lutein with bovine and caprine caseins and their impact on lutein chemical stability in emulsion systems: Effect of arabinogalactan. Journal of Dairy Science, 101(1), 18-27. https://doi.org/10.3168/jds.2017-13105.

Paiva, Paulo Henrique C., Coelho, Yara L., da Silva, Luis Henrique M., Pinto, Maximiliano S., Vidigal, Márcia Cristina T. R., \& Pires, Ana Clarissa dos S. (2020). Influence of protein conformation and selected Hofmeister salts on bovine serum albumin/lutein complex formation. Food Chemistry, 305, 125463. http://doi.org/10.1016/j. foodchem.2019.125463.

Pan, Kang, Zhong, Qixin, \& Baek, Seung Joon (2013). Enhanced Dispersibility and Bioactivity of Curcumin by Encapsulation in Casein Nanocapsules. Journal of Agricultural and Food Chemistry, 61(25), 6036-6043. https://doi.org/10.1021/ jf400752a.

Rahimi Yazdi, S., \& Corredig, M. (2012). Heating of milk alters the binding of curcumin to casein micelles. A fluorescence spectroscopy study. Food Chemistry, 132(3), 1143-1149. https://doi.org/10.1016/j.foodchem.2011.11.019.

Scatchard, George (1949). The Attractions of Proteins for Small Molecules and Ions Annals of the New York Academy of Sciences, 51, 660.

Tavares, Guilherme M., Croguennec, Thomas, Carvalho, Antonio F., \& Bouhallab, Saïd (2014). Milk proteins as encapsulation devices and delivery vehicles: Applications and trends. Trends in Food Science \& Technology, 37(1), 5-20. https://doi.org/ 10.1016/j.tifs.2014.02.008.

Teale, F. W., \& Weber, G. (1957). Ultraviolet fluorescence of the aromatic amino acids. The Biochemical journal, 65(3), 476-482. https://doi.org/10.1042/bj0650476.

van de Weert, Marco (2010). Fluorescence Quenching to Study Protein-ligand Binding: Common Errors. Journal of Fluorescence, 20(2), 625-629. https://doi.org/10.1007/ s10895-009-0572-x.

Velazquez-Campoy, Adrian, \& Freire, Ernesto (2006). Isothermal titration calorimetry to determine association constants for high-affinity ligands. Nature Protocols, 1(1), 186-191. https://doi.org/10.1038/nprot.2006.28.

Walstra, P., \& Jenness, R. (1984). Dairy chemistry and physics. New York: Wiley.

Walstra, P., Wouters, J. T. M., \& Geurts, T. J. (2006). Dairy Science Technology (2nd ed.). New York: Taylor \& Francis Group.

Woodside, Jayne V., McGrath, Alanna J., Lyner, Natalie, \& McKinley, Michelle C. (2015). Carotenoids and health in older people. Maturitas, 80(1), 63-68. https://doi.org/ 10.1016/j.maturitas.2014.10.012.

Yi, Jiang, Fan, Yuting, Yokoyama, Wallace, Zhang, Yuzhu, \& Zhao, Liqing. (2016). Characterization of milk proteins-lutein complexes and the impact on lutein chemical stability. Food Chemistry, 200(Supplement C), 91-97. http://doi.org/ 10.1016/j.foodchem.2016.01.035.

Zhang, Yue, Wright, Edward, \& Zhong, Qixin (2013). Effects of pH on the Molecular Binding between $\beta$-Lactoglobulin and Bixin. Journal of Agricultural and Food Chemistry, 61(4), 947-954. https://doi.org/10.1021/jf303844w.

Zhang, Yue, \& Zhong, Qixin (2012a). Binding between Bixin and Whey Protein at pH 7.4 Studied by Spectroscopy and Isothermal Titration Calorimetry. Journal of Agricultural and Food Chemistry, 60(7), 1880-1886. https://doi.org/10.1021/jf2050262.

Zhang, Yue, \& Zhong, Qixin (2012b). Effects of Thermal Denaturation on Binding between Bixin and Whey Protein. Journal of Agricultural and Food Chemistry, 60(30), 7526-7531. https://doi.org/10.1021/jf3021656.

Zhang, Yue, \& Zhong, Qixin (2013). Probing the binding between norbixin and dairy proteins by spectroscopy methods. Food Chemistry, 139(1), 611-616. https://doi. org/10.1016/j.foodchem.2013.01.073.

Zhu, Junxiang, Wang, Cong, Gao, Jun, Wu, Hao, \& Sun, Qingjie (2019). Aggregation of Fucoxanthin and Its Effects on Binding and Delivery Properties of Whey Proteins. Journal of Agricultural and Food Chemistry, 67(37), 10412-10422. https://doi.org/ 10.1021/acs.jafc.9b03046. 